\title{
Erratum to: Arrhythmogenic right ventricular cardiomyopathy secondary to adipose infiltration as a cause of episodic collapse in a horse
}

\author{
Alexandra G. Raftery ${ }^{1 *}$, Nerea Cuesta-Garcia², Hal Thompson ${ }^{2}$ and David G. M. Sutton ${ }^{1}$
}

\section{Erratum}

After publication of the original article [1] it was brought to our attention that author Nerea Cuesta-Garcia was incorrectly included as Nuria C. Garcia.

The correct spelling of the name is included in the author list of this erratum.

\section{Author details \\ ${ }^{1}$ Weipers Centre Equine Hospital, University of Glasgow, Bearsden Road, Glasgow G611QH, UK. ²Department of Pathology, University of Glasgow, Bearsden Road, Glasgow G611QH, UK.}

Received: 5 June 2017 Accepted: 5 June 2017

Published online: 07 June 2017

\section{Reference}

1. Raftery, et al. Arrhythmogenic right ventricular cardiomyopathy secondary

to adipose infiltration as a cause of episodic collapse in a horse. Ir Vet J.

2015;68:24. doi:10.1186/s13620-015-0052-3.

\footnotetext{
* Correspondence: alexandra.raftery@googlemail.com

${ }^{1}$ Weipers Centre Equine Hospital, University of Glasgow, Bearsden Road,

Glasgow G611QH, UK
} 